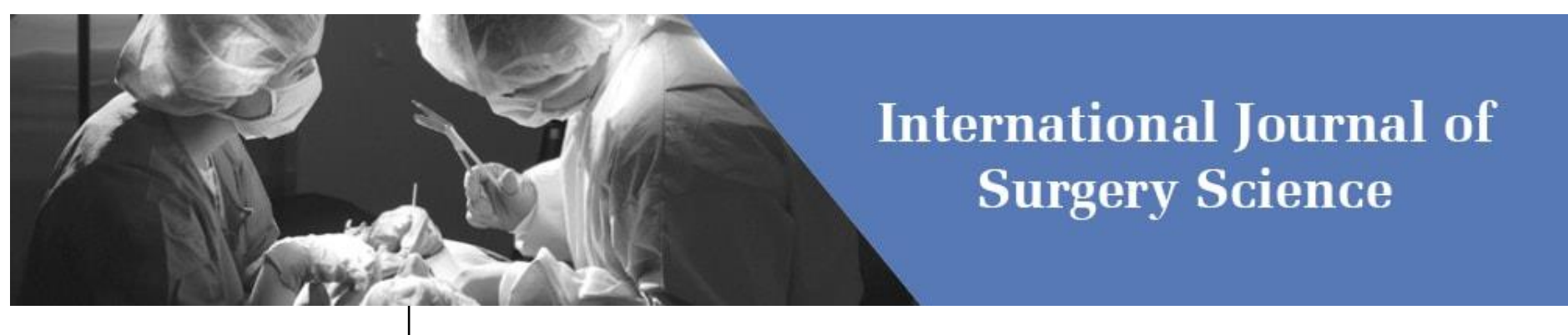

E-ISSN: 2616-3470

P-ISSN: 2616-3462

(C) Surgery Science

www.surgeryscience.com

2021; 5(1): 606-608

Received: 25-10-2020

Accepted: 01-12-2020

Dr. Prashanth Kumar K

Associate Professor, Department of Surgery, Srinivas Institute of

Medical Sciences, Mangalore,

Karnataka, India
Corresponding Author: Dr. Prashanth Kumar K Associate Professor, Department of Surgery, Srinivas Institute of Medical Sciences, Mangalore, Karnataka, India

\section{A study of clinical and surgical management of hernia}

\section{Dr. Prashanth Kumar K}

\section{DOI: https://doi.org/10.33545/surgery.2021.v5.i1g.643}

\section{Abstract}

Hernia is the protrusion of viscera outside the body cavities which it was destined to stay in. The hernias can also occur internally from displacement of viscera from one cavity to the other. Such displacements are called as the internal hernias. The hiatal hernias are the commonest examples of these. The symptoms can be vague initially and the patients can neglect these for a long time since the signs and symptoms would be less initially. But sudden dreaded complications will always be associated with these which should be looked into. This study puts in an effort to find the pattern for the clinical presentation and also most common treatment involved for such cases.

Keywords: Incisional hernia, management, clinical

\section{Introduction}

Agrawal $\mathrm{M}$ et al. ${ }^{[3]}$ analysed 100 cases of incisional hernia, $42 \%$ of patients were in the age group 41-45 years, followed by 51-60 years (30\%), 31-40 years (17\%) and 21-30 years (11\%). In a similar study done by Ellis et al. ${ }^{[4]} 48 \%$ of patients developing incisional hernia belonged to the age group of 31-40 years. The mean age of incisional hernia in the present study was 40.7 years, which was comparable with the study by Ellis et al (49.4 years). In the study by Agrawal et al, female-to-male ratio was 1.6:1. In a similar study done by Ellis and Heddle, femaleto-male ratio was 4.8:1. Millbourn et al. ${ }^{[5]}$ reported an incidence of $64.6 \%$ female population in their study of 383 patients. The reason behind this could be laxity of the abdominal muscles due to multiple pregnancies and increased number of lower abdominal incisions in females. J.B. Shah et al. ${ }^{[6]}$ and Goel et al. series have male-to-female ratio of $1: 1.17$ and $1: 1.25$, respectively. In the present study, male: female ratio was 1:6 being more common in females. On clinical examination in the study by Agrawal et al. $386 \%$ of cases presented with reducible lump, only three cases had severe pain with strangulation. Incisional hernia occurred between 6 months to 1 year of surgical intervention in $48 \%$ of cases. $68 \%$ patients had previous surgeries through lower abdominal incisions, $18 \%$ patients with upper midline incision, $10 \%$ patients with right paramedian incision and $4 \%$ with left paramedian incision. In the study by Bucknell et al. $42 \%$ cases presented with hernia 1-5 years after primary surgery. 68\% patients who had lower abdominal incisions developed incisional hernia followed by $18 \%$ patients with upper midline incision, $10 \%$ patients with right paramedian incision and $4 \%$ with left paramedian incision. Millbourn et al. and Carlson found that this type of hernia is common in females undergoing gynaecological surgeries in which lower abdominal incisions are made ${ }^{[7]}$. Some authors believe that incisional hernia rates do not differ by type of incision and incision should be driven by surgeon's preference with respect to the patient's disease and anatomy. Ponka series ${ }^{[8]}$ stated that repeated surgeries $(25 \%)$ could be one of the risk factors in developing incisional hernia. In various studies $[9,10]$ wound infection following the surgery was the main factor for the development of incisional hernia. The other common factors were burst abdomen following infection and chronic cough during postoperative period. In a research done by Bose et al. ${ }^{[11]}$ in their study documented the common risk factors as wound infection in $53.63 \%$ of cases, obesity in $30 \%$ and COPD in $20.90 \%$. In the study by Agrawal et al. most common cause for incisional hernia was found to be postoperative infection (47\%), followed by cough (10\%) and early return to work $(2 \%)$. In the present study risk factors promoting incisional hernias was wound infection accounted for $40 \%$, obesity (30\%) and COPD in $8 \%$ of cases.

This study puts in an effort to find the pattern for the clinical presentation and also most common treatment involved for such cases. 


\section{Aims and Objectives}

To study the clinical features and management of hernia.

\section{Materials and Methods}

A total of 134 cases were studied. This study was done in Srinivas Institute of Medical Sciences, Mangalore.

This study was done from March 2017 to August 2019.

\section{Exclusion criteria}

Included patients beyond 70 years of age and incisional hernias associated with other abdominal wall hernias.

A detailed history of all the patients was taken and a thorough clinical examination was done to determine the type and cause of hernia.

\section{Results}

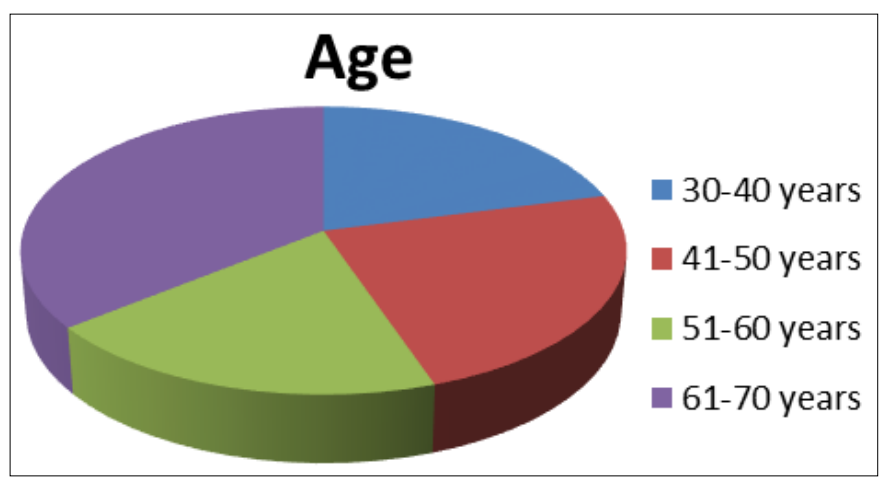

Graph 1: Age Distribution:

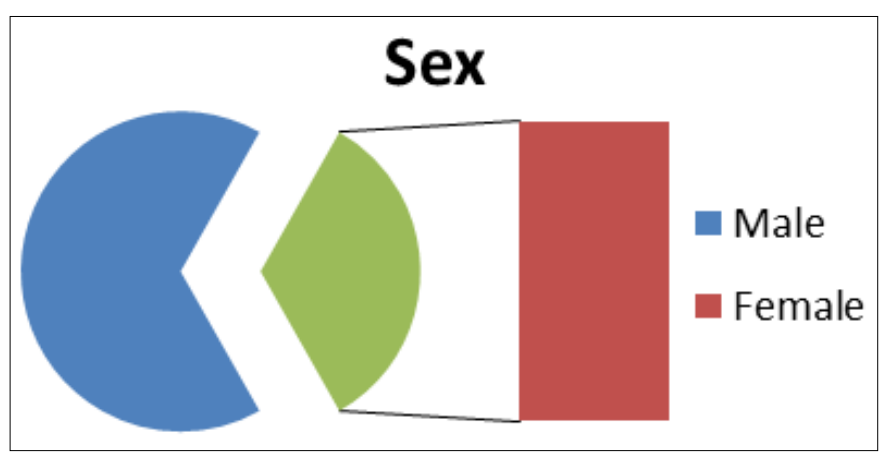

Graph 2: Sex Distribution

Table 1: Signs and Symptoms

\begin{tabular}{|c|c|}
\hline Abdominal swelling & 107 \\
\hline Pain & 81 \\
\hline Obstruction & 01 \\
\hline Fever & 09 \\
\hline
\end{tabular}

Table 2: Treatment

\begin{tabular}{|c|c|}
\hline Anatomical repair & 03 \\
\hline Onlay mesh & 02 \\
\hline Sublay mesh & 128 \\
\hline Underlay mesh & 01 \\
\hline
\end{tabular}

\section{Discussion}

Most men with hernias develop two symptoms: a dull pain or ache, and a bulge in the groin or scrotum. The symptoms usually develop gradually, but they can sometimes begin abruptly, in which case heavy lifting is usually the precipitating event. In some men, an ache or heavy feeling can precede the bulge by weeks or even months. In others, the bulge is entirely painless; sometimes in fact, hernias develop so silently that they are first detected by a physician in the course of a routine physical examination.

Early in the course of a hernia, the bulge is intermittent, being noticeable when a man strains or when he stands, but not while he's lying down. The bulge occurs when abdominal contents - a part of the intestine, the fatty tissue that surrounds the bowel, or both - protrude through the opening, pushing on the skin. Hernias that come and go - either spontaneously or as a result of gentle manual pressure on the bulge - are called reducible hernias.

Reducible hernias can be uncomfortable or unsightly, but they're not serious. But hernias that cannot be reduced are another matter. Such incarcerated hernias are more likely to be painful, and they can develop a second complication, strangulation, when pressure interferes with the blood supply of the bowel. All strangulated hernias are painful and tender; in short order, the pain becomes severe and the patient develops nausea, vomiting, abdominal swelling, and fever; prompt surgery is mandatory. Fortunately, these complications are uncommon in indirect inguinal hernias and less common still in direct inguinal hernias. But since only a small minority of inguinal hernias will become incarcerated or strangulated, most men face the luxury (and responsibility) of deciding which treatment is best. Unfortunately, this is not the case with all types of hernias. About $40 \%$ of femoral hernias (see box), which occur in the groin near the thigh, require emergency surgery for strangulation or incarceration. All femoral hernias should be repaired promptly.

\section{Other hernias}

Femoral hernias. Accounting for only $4 \%$ of groin hernias, femoral hernias are actually four times more common in women than men. They typically present as a bulge in the upper thigh, just below the groin.

Umbilical hernias. Abdominal contents bulge through a defect in the umbilicus, or belly button.

Ventral hernias. Abdominal contents bulge through a separation between the two large rectus muscles that join at the middle of the abdomen to form the abdominal wall.

Incisional hernias. Tissues bulge through a surgical incision; usually abdominal contents press through an abdominal scar. One study reported that mesh repairs are superior to conventional suture repairs, even for small incisional hernias.

Hiatal hernias. The stomach bulges up through the diaphragm, the large muscle that separates the abdomen from the chest.

\section{Conclusion}

Prompt diagnosis and treatment is the need of the hour for such pathologies.

\section{References}

1. Bucknall TE, Cox PJ, Ellis H. Burst abdomen and incisional hernia: a prospective study of 1129 major laparotomies. Br Med J 1982;284(6320):931-933.

2. Mudge $\mathbf{M}$, Hughes LE. Incisional hernia: a 10 year prospective study of incidence and attitudes. Br J Surg 1985;72(1):70-71.

3. Agrawal M, Singh H, Sharma SP et al. Prevalence, clinical presentation, and management of incisional hernia in the Indian population: a cross-sectional study. Int. J Sci Stud 2016;4(7):51-54.

4. Ellis H, Heddle R. Does the peritoneum need to be closed at laparotomy? Br J Surg 1977;64(10):733-736. 
5. Millbourn D, Cengiz Y, Israelsson LA. Effect of stitch length on wound complications after closure of midline incisions: a randomized controlled trial. Arch Surg 2009;144(11):1056-1059.

6. Shah JB. Incisional hernia. A study of 50 cases. Indian Journal of Surgery 1977;39:353-356.

7. Carlson MA. New developments in abdominal wall closure. Chirurg 2000;71(7):743-753.

8. Ponka JL. Hernias of the abdominal wall. 1st edn. Philadelphia, London: WB Saunders, 1980, 186-190.

9. Seiler CM, Deckert A, Diener MK, et al. Midline versus transverse incision in major abdominal surgery: a randomized, double-blind equivalence trial (POVATI: ISRCTN60734227). Ann Surg 2009;249(6):913-920. Jebmh.com Original Research Article J. Evid. Based Med. Healthc., pISSN- 2349-2562, eISSN- 2349-2570/ Vol. 4/Issue 66/Aug. 17, 2017 Page 3952

10. Jenkins TP. The burst abdominal wound: a mechanical approach. Br J Surg 1976;63(11):873-876.

11. Bose SM, Lal Roshan, Kalra Manju, et al. Ventral hernia-a review of 175 cases. Indian Journal of Surgery 1999;61(3):180-184. 